ISSN 1420-3049

www.mdpi.com/journal/molecules

\title{
Communication
}

\section{Intramolecular C-H...O Hydrogen Bonding in 1,4-Dihydropyridine Derivatives}

\section{Marina Petrova *, Ruslan Muhamadejev, Brigita Vigante, Brigita Cekavicus, Aiva Plotniece, Gunars Duburs and Edvards Liepinsh}

Latvian Institute of Organic Synthesis Aizkraukles 21 Street, Riga LV-1006, Latvia;

E-Mails: muhamadejev@osi.lv (R.M.); vigante@osi.lv (B.V.); arkady@osi.lv (B.C.); aiva@osi.lv (A.P.); gduburs@osi.lv (G.D.); edv@osi.lv (E.L.)

* Author to whom correspondence should be addressed; E-Mail: marina@osi.lv;

Tel.: +371-67014900.

Received: 26 July 2011; in revised form: 8 September 2011 / Accepted: 9 September 2011/

Published: 19 September 2011

\begin{abstract}
The diastereotopy of the methylene protons at positions 2 and 6 in 1,4dihydropiridine derivatives with various substituents has been investigated. NMR spectroscopy and quantum chemistry calculations show that the $\mathrm{CH} \cdots \mathrm{O}$ intramolecular hydrogen bond is one of the factors amplifying the chemical shift differences in the ${ }^{1} \mathrm{H}-\mathrm{NMR}$ spectra.
\end{abstract}

Keywords: 1,4-dihydropyridines; bromination; nucleophilic substitution; hydrogen bond; NMR spectra; quantum chemical calculations

\section{Introduction}

The 1,4-dihydropyridine (1,4-DHP) scaffold is a common component of pharmacologically active molecules which possess a variety of biological activities [1]. Several 1,4-DHP derivatives play an important role in regulating the decrease or increase of the penetration of calcium ions through membranes into cells. Substituents at the 2,6-, 3,5-, 4- and 1- positions of 1,4-DHP derivatives influence their structure-activity relationships, so structural and conformational investigations of these systems are important to gain insight into the mechanisms of their physiological action [2]. 


\section{Results and Discussion}

In recent years many studies attempting to modify the 2,6-methyl groups of 1,4-DHP by introducing various substituents have been performed [3-6]. On the other hand cationic amphiphilic 1,4-DHP derivatives have gained significance as useful transport molecules for the delivery of nucleotides into target cells $[4,7]$.

Our attention was drawn to the fact that the $\mathrm{CH}_{2} \mathrm{X}$ protons of substituents in positions 2 and 6 of symmetrically substituted 1,4-dihydropyridine rings (compounds 1-3, 5, Table 1) become diastereotopic in the presence of different substituents at position 4, thereby, providing an $\mathrm{AB}$ system in the corresponding ${ }^{1} \mathrm{H}-\mathrm{NMR}$ spectra. The extent of the observed non-equivalence of the methylene protons should be influenced by the spatial conformation of side chains in the molecule and/or the anisotropy of the substituents.

Table 1. Characterization of compounds 1-5.

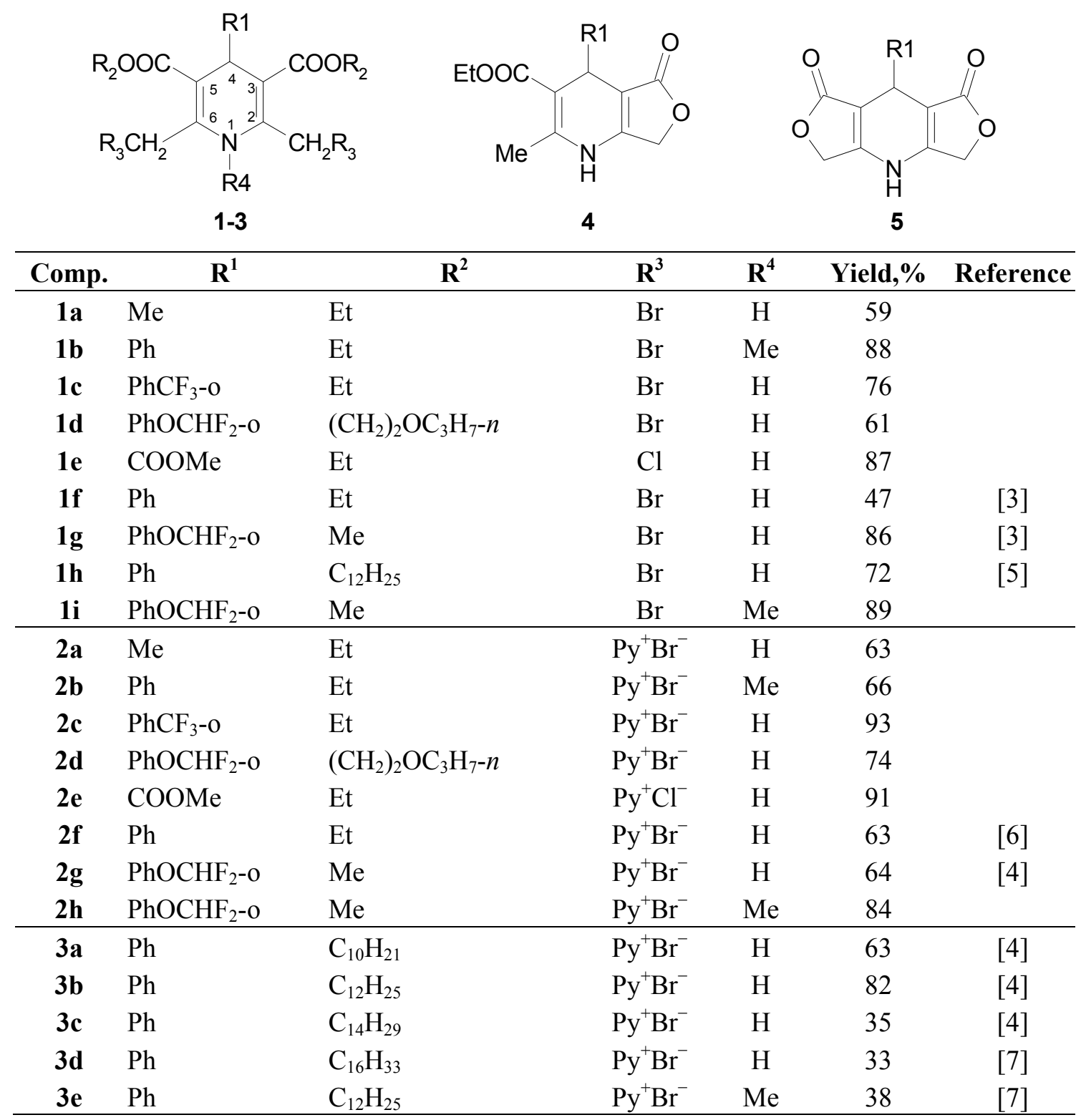


Table 1. Cont.

\begin{tabular}{|c|c|c|c|c|c|}
\hline Comp. & $\mathbf{R}^{1}$ & $\mathbf{R}^{2}$ & $\begin{array}{ll}\mathbf{R}^{3} & \mathbf{R}^{4} \\
\end{array}$ & Yield,\% & Reference \\
\hline $\mathbf{4 a}$ & $\mathrm{Ph}$ & & & 20 & [10] \\
\hline $4 f$ & $\mathrm{PhOCHF}_{2}-\mathrm{O}$ & & & 33 & [11] \\
\hline $5 a$ & $\mathrm{Ph}$ & & & 50 & [12] \\
\hline $5 f$ & $\mathrm{PhOCHF}_{2}-\mathrm{O}$ & & & 60 & [13] \\
\hline
\end{tabular}

The synthetic pathway for obtaining 1,4-dihydropyridine derivatives bearing substituents on the 2,6-methylene groups (Table 1) involved Hantzsch synthesis, followed by bromination of the methyl groups with NBS and nucleophilic substitution of bromine by pyridine giving the target compounds 1a-d, i and 2a-d, h (Scheme 1).

Scheme 1. Synthesis of compounds 1 and 2.

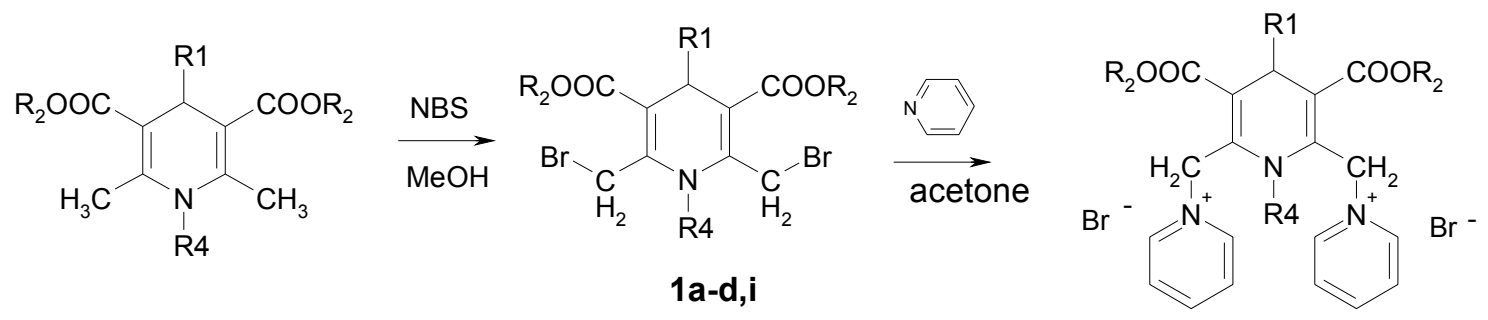

2a-d,h

A different approach was elaborated for the synthesis of 4-methoxycarbonyl derivative 1e (Scheme 2). Thus, the condensation of ethyl 4-chloroacetoacetate with glyoxylic acid monohydrate in methanol at $\mathrm{rt}$ in the presence of piperidine/acetate as catalyst provided (E,Z)-2-(2-chloroacetyl)-but-2enedioic acid 1-ethyl ester, which was used without isolation in the next reaction with ethyl 3-amino-4chlorobut-2-enoate. The obtained 3,5-diethyl 2,6-bis(chloromethyl)-1,4-dihydropyridine-3,4,5-tricarboxylate was esterified with methanol using conc. sulfuric acid as catalyst to afford compound 1e. The target compound $\mathbf{2 e}$ was successfully obtained via nucleophilic substitution of chlorine by pyridine in the presence of potassium iodide in dry acetone.

Scheme 2. Synthesis of compounds 1e, 2e.
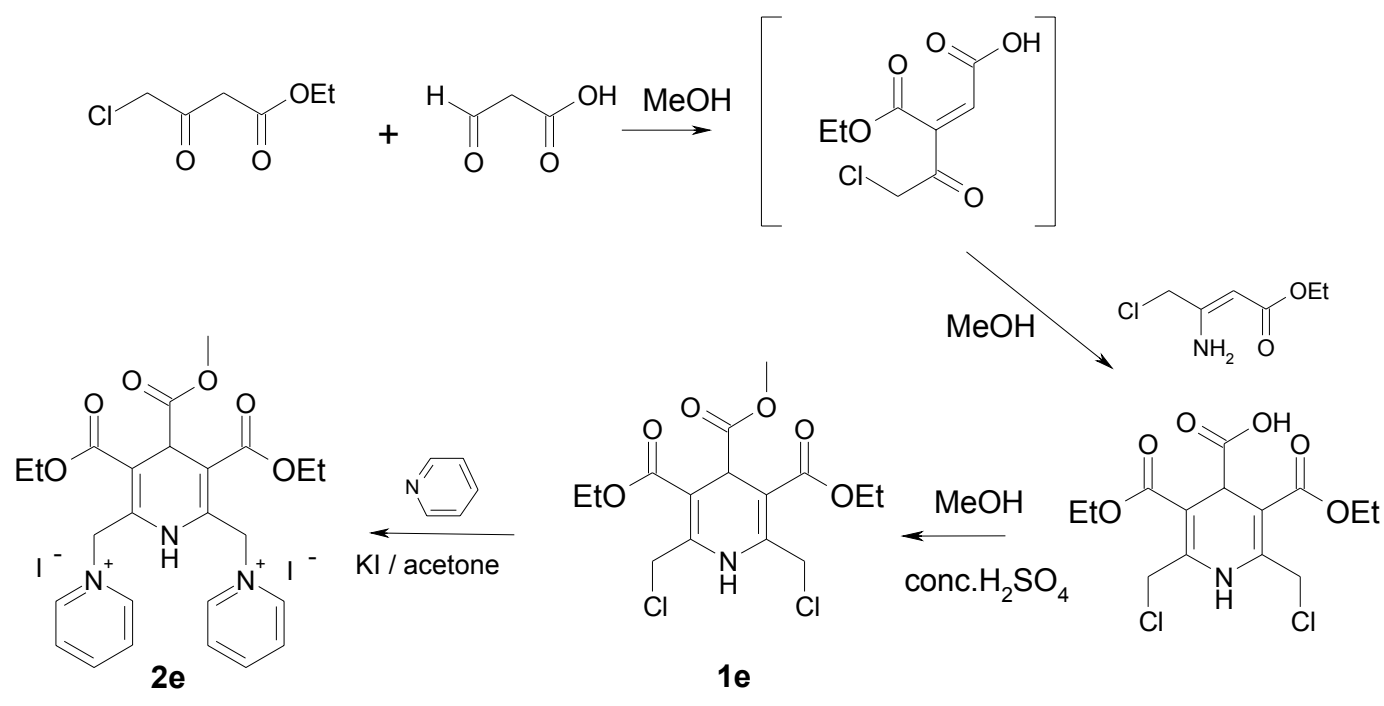
Compounds $\mathbf{1 f}-\mathbf{h}, \mathbf{2} \mathbf{f}-\mathbf{g}, \mathbf{3 a}-\mathbf{e}, \mathbf{4 a}, \mathbf{f}$ and $\mathbf{5 a}, \mathbf{f}$ were prepared according to the literature, as mentioned in Table 1. The 4-substituent in the molecule is located at a considerable distance from the 2- (6-) methylene group, and the experimentally observed difference in the ${ }^{1} \mathrm{H}-\mathrm{NMR}$ chemical shifts of the $\mathrm{CH}_{2}$ groups in cyclic lactones 4-5 does not exceed $0.08 \mathrm{ppm}$ (Table 2); a similar value was observed in [8]. However, its potential anisotropic influence on the $2,6-\mathrm{CH}_{2}$ methylene proton chemical shifts can't be ignored. In monocyclic derivatives 1-3 the conformation of the 3,5-ethoxycarbonyl groups should be another important factor in the anisotropy. Indeed in these compounds the chemical shift difference for $\mathrm{CH}_{2} \mathrm{X}$ protons becomes very significant (Table 2), so we can assume that the difference in chemical shifts of $\mathrm{CH}_{2} \mathrm{X}$ groups in 1-3 induced by the anisotropy of the 4-substituent may also be influenced by the position of these protons relative to the 3,5-alkoxycarbonyl substituents. In order to study the substituent influence on the magnetic nonequivalence of the mentioned ${ }^{1} \mathrm{H}-\mathrm{NMR}$ signals, quantum chemical studies were carried out for some derivatives of 1,4-DHP (compounds 1-5). The obtained data are presented in Table 3.

Table 2. ${ }^{1} \mathrm{H}-\mathrm{NMR}$ data of compounds 1-5.

\begin{tabular}{|c|c|c|c|c|c|c|c|}
\hline Comp. & Solvent & $\delta \mathrm{NH}$ & $\delta \mathbf{H}_{B}$ & ${ }^{1} \mathbf{J}\left(\mathbf{C}, \mathbf{H}_{\mathrm{B}}\right)$ & $\delta \mathbf{H}_{\mathrm{A}}$ & ${ }^{1} \mathbf{J}\left(\mathbf{C}, \mathbf{H}_{\mathrm{A}}\right)$ & ${ }^{2} \mathbf{J}(\mathbf{H}, \mathbf{H})$ \\
\hline \multirow{2}{*}{$1 \mathrm{a}$} & $\mathrm{CDCl}_{3}$ & 6.35 & 4.89 & 159 & 4.51 & 157 & 11.5 \\
\hline & DMSO & 9.44 & 4.69 & & 4.40 & & 9.6 \\
\hline \multirow{2}{*}{$1 \mathrm{~b}$} & $\mathrm{CDCl}_{3}$ & & 4.96 & & 4.82 & & 11.0 \\
\hline & DMSO & & 5.17 & & 4.87 & & 11.3 \\
\hline \multirow{2}{*}{$1 \mathrm{c}$} & $\mathrm{CDCl}_{3}$ & 6.49 & 4.81 & 159 & 4.66 & 157 & 11.6 \\
\hline & DMSO & 9.67 & 4.61 & 158 & 4.56 & 157 & 9.9 \\
\hline \multirow{2}{*}{ 1d } & $\mathrm{CDCl}_{3}$ & 6.55 & 4.86 & & 4.57 & & 11.8 \\
\hline & DMSO & 9.62 & 4.67 & & 4.53 & & 9.7 \\
\hline \multirow{2}{*}{$1 \mathrm{e}$} & $\mathrm{CDCl}_{3}$ & 7.37 & 5.19 & 160 & 4.74 & 158 & 14.6 \\
\hline & DMSO & 9.78 & 4.93 & 158 & 4.48 & 156 & 11.1 \\
\hline \multirow{2}{*}{ 1f } & $\mathrm{CDCl}_{3}$ & 6.45 & 4.91 & 159 & 4.63 & 156.4 & 11.8 \\
\hline & DMSO & 9.58 & 4.67 & 160 & 4.57 & 158.7 & 9.6 \\
\hline \multirow{2}{*}{$1 \mathrm{~g}$} & $\mathrm{CDCl}_{3}$ & 6.56 & 4.86 & & 4.62 & & 11.3 \\
\hline & DMSO & 9.65 & 4.62 & & 4.59 & & 9.7 \\
\hline \multirow{2}{*}{$1 \mathrm{~h}$} & $\mathrm{CDCl}_{3}$ & 6.45 & 4.92 & 158 & 4.63 & 156 & 11.5 \\
\hline & DMSO & 9.62 & 4.68 & 159 & 4.59 & 157 & 9.7 \\
\hline \multirow{2}{*}{$1 \mathbf{i}$} & $\mathrm{CDCl}_{3}$ & & 4.91 & & 4.84 & & 11.0 \\
\hline & DMSO & & 5.18 & & 4.85 & & 11.4 \\
\hline \multirow{2}{*}{$2 a$} & $\mathrm{CDCl}_{3}$ & 10.88 & 6.28 & & 5.76 & & 14.1 \\
\hline & DMSO & 10.10 & 5.99 & & 5.49 & & 15.0 \\
\hline \multirow{2}{*}{$2 b$} & $\mathrm{CDCl}_{3}$ & & 6.82 & 152.1 & 6.59 & 146.3 & 15.6 \\
\hline & DMSO & & 6.45 & 152.2 & 5.77 & 146.2 & 16.0 \\
\hline \multirow{2}{*}{$2 c$} & $\mathrm{CDCl}_{3}$ & 10.98 & 6.35 & 153.1 & 5.97 & 147.1 & 13.6 \\
\hline & DMSO & 10.48 & 5.97 & 151.1 & 5.66 & 149.1 & 15.1 \\
\hline \multirow{2}{*}{ 2d } & $\mathrm{CDCl}_{3}$ & 10.80 & 6.16 & & 6.11 & & 14.1 \\
\hline & DMSO & 10.15 & 5.90 & 150.1 & 5.62 & 149.2 & 14.9 \\
\hline \multirow{2}{*}{$2 e$} & $\mathrm{CDCl}_{3}$ & 10.31 & 6.30 & & 6.06 & & 14.1 \\
\hline & DMSO & 10.20 & 5.97 & & 5.64 & & 15.6 \\
\hline
\end{tabular}


Table 2. Cont.

\begin{tabular}{|c|c|c|c|c|c|c|c|}
\hline Comp. & Solvent & $\delta \mathrm{NH}$ & $\delta \mathbf{H}_{\mathrm{B}}$ & ${ }^{1} \mathrm{~J}\left(\mathrm{C}, \mathrm{H}_{\mathrm{B}}\right)$ & $\delta \mathbf{H}_{\mathbf{A}}$ & ${ }^{1} \mathbf{J}\left(\mathbf{C}, \mathbf{H}_{\mathrm{A}}\right)$ & ${ }^{2} \mathbf{J}(\mathbf{H}, \mathbf{H})$ \\
\hline \multirow{2}{*}{$2 f$} & $\mathrm{CDCl}_{3}$ & 10.92 & 6.38 & 150.6 & 5.92 & 146.5 & 13.6 \\
\hline & DMSO & 10.34 & 6.08 & 151.9 & 5.63 & 146.4 & 15.3 \\
\hline \multirow{2}{*}{$2 \mathrm{~g}$} & $\mathrm{CDCl}_{3}$ & 10.88 & 6.24 & & 6.10 & & 13.7 \\
\hline & DMSO & 10.31 & 5.94 & & 5.46 & & 14.9 \\
\hline \multirow{2}{*}{$2 \mathrm{~h}$} & $\mathrm{CDCl}_{3}$ & & 6.84 & & 6.62 & & 15.8 \\
\hline & DMSO & & 6.39 & & 5.77 & & 16.2 \\
\hline \multirow{2}{*}{$3 \mathbf{a}$} & $\mathrm{CDCl}_{3}$ & 10.96 & 6.40 & 150.7 & 5.89 & 146.5 & 13.9 \\
\hline & DMSO & 10.21 & 6.08 & 151.1 & 5.56 & 145.4 & 15.1 \\
\hline \multirow{2}{*}{$3 \mathbf{b}$} & $\mathrm{CDCl}_{3}$ & 10.95 & 6.40 & 151.4 & 5.89 & 146.3 & 13.9 \\
\hline & DMSO & 10.12 & 6.07 & 152.4 & 5.53 & 146.3 & 15.0 \\
\hline \multirow{2}{*}{$3 c$} & $\mathrm{CDCl}_{3}$ & 10.92 & 6.32 & 150.1 & 5.86 & 146.2 & 13.8 \\
\hline & DMSO & 10.28 & 6.08 & 152.1 & 5.56 & 146.4 & 15.1 \\
\hline \multirow{2}{*}{ 3d } & $\mathrm{CDCl}_{3}$ & 10.96 & 6.40 & 148.3 & 5.89 & 146.2 & 13.9 \\
\hline & DMSO & 10.12 & 6.07 & & 5.53 & & 15.2 \\
\hline \multirow{2}{*}{$3 e$} & $\mathrm{CDCl}_{3}$ & & 6.73 & 152.5 & 6.56 & 150.2 & 16.1 \\
\hline & DMSO & & 6.48 & 152.5 & 5.78 & 147.5 & 16.5 \\
\hline \multirow{2}{*}{$4 a$} & $\mathrm{CDCl}_{3}$ & 8.30 & 4.52 & and & 4.47 & & 16.7 \\
\hline & DMSO & 9.74 & 4.84 & and & 4.74 & & 16.5 \\
\hline $4 f$ & $\mathrm{CDCl}_{3}$ & 6.42 & 4.69 & and & 4.65 & & 16.4 \\
\hline $5 a$ & DMSO & 9.91 & 4.72 & and & 4.65 & & 16.0 \\
\hline $5 f$ & DMSO & 9.97 & 4.64 & and & 4.60 & & 16.2 \\
\hline
\end{tabular}

Table 3. Comparison of H-bond parameters in model compounds $\mathbf{1 f}, \mathbf{1 b}$ and $\mathbf{2 b}, \mathbf{2} \mathbf{f}$ and $\mathbf{3 b}$.

\begin{tabular}{lcccc}
\hline Compound & $\mathbf{C 2}(\mathbf{C H} \cdots \mathbf{O})$ & $\mathbf{C 6}(\mathbf{C H} \cdots \mathbf{O})$ & $\mathbf{C 2} \mathbf{p y r}(\mathbf{C H} \cdots \mathbf{O})$ & $\mathbf{C 6} \mathbf{p y r}(\mathbf{C H} \cdots \mathbf{O})$ \\
\hline & $2.508 \AA$, & $2.511 \AA$, & & \\
1f & $\left(86.6^{\circ}\right)$ & $\left(86.5^{\circ}\right)$ & - & - \\
& $2.376 \AA$, & $2.374 \AA$, & & \\
& $\left(93.6^{\circ}\right)$ & $\left(93.7^{\circ}\right)$ & & - \\
1b & $2.032 \AA$, & $2.073 \AA$, & & \\
& $\left(131.5^{\circ}\right)$ & $\left(126.0^{\circ}\right)$ & & $2.152 \AA$, \\
2f & $2.329 \AA$, & $2.168 \AA$, & $2.629 \AA$, & $\left(137.3^{\circ}\right)$ \\
& $\left(99.6^{\circ}\right)$ & $\left(117.7^{\circ}\right)$ & $\left(89.7^{\circ}\right)$ & $2.913 \AA$, \\
2b & $2.254 \AA$, & $2.198 \AA$, & $2.544 \AA$, & $\left(87.5^{\circ}\right)$ \\
& $\left(103.9^{\circ}\right)$ & $\left(107.7^{\circ}\right)$ & $\left(94.0^{\circ}\right)$ & $2.849 \AA$, \\
3b & $2.341 \AA$, & $2.366 \AA$, & $2.591 \AA$, & $\left(82.121^{\circ}\right)$ \\
\hline
\end{tabular}

Signals of the AB protons of the 2,6-methylene groups for compounds $\mathbf{1 - 5}$ are easily distinguishable in the ${ }^{1} \mathrm{H}-\mathrm{NMR}$ spectra by their $11-15 \mathrm{~Hz}$ geminal ${ }^{2} J$ coupling constants. The values of the constants for compounds $\mathbf{1}$ are less than for compounds 2 and $\mathbf{3}$. Neighbouring $\pi$-bonds of the pyridines in 2, 3 usually result in an increase of the absolute value of the constants ${ }^{2} J$.

According to literature data [9], increasing the polarity of the medium usually slightly increases the negative contribution to the geminal coupling, and if its sign is negative, the absolute value increases. 
Such effect is observed in the N-methyl-substituted derivatives $\mathbf{1 b}, \mathbf{1 i}$ and in compounds $\mathbf{2}, \mathbf{3}$ where $\left|{ }^{2} J_{\text {cdc13 }}\right|<\left.\right|^{2} J_{\text {dmso }} \mid$. However, for compounds $\mathbf{1 a}$ and $\mathbf{1 c}-\mathbf{h}$, contrary to the literature data, the ${ }^{2} J$ values decrease by about $2 \mathrm{~Hz}$ on going from $\mathrm{CDCl}_{3}$ to DMSO solution. The unusual behaviour of the geminal couplings for compounds 1a, $\mathbf{1} \mathbf{c}-\mathbf{h}$ may be explained by the variation of the dihedral angle between the methylene group protons and 1,4-DHP cycle in distribution of rotamers around the $\mathrm{C}_{2,6}-\mathrm{CH}_{2} \mathrm{X}$ bond.

Formation of intermolecular hydrogen bonds between the $\mathrm{NH}$ group and solvent DMSO moves the resonance signal of $\mathrm{NH}$ proton to a higher-frequency field $\sim 3 \mathrm{ppm}$ (Table 2). Contrary in compounds $\mathbf{2 a}, \mathbf{c}-\mathbf{g}$ and $\mathbf{3 a}-\mathbf{d}$, the resonance signal of the $\mathrm{NH}$ proton moves to a lower-frequency field $\sim 0.5-1.1 \mathrm{ppm}$ on going from $\mathrm{CDCl}_{3}$ to DMSO. The reason for this anomalous behaviour of the $\mathrm{NH}$ proton could be that in $\mathrm{CDCl}_{3}$ solutions of these compounds the $\mathrm{CH}_{2} \mathrm{Py}$ substituent is strongly oriented and $\mathrm{NH}$ proton is located in a zone of negative anisotropy of the pyridinium ring. This is confirmed by calculations (Figure 1).

Figure 1. The calculated optimal conformations in compounds $\mathbf{1 f}, \mathbf{1 b}$ and $\mathbf{2 f}, \mathbf{2 b}$.

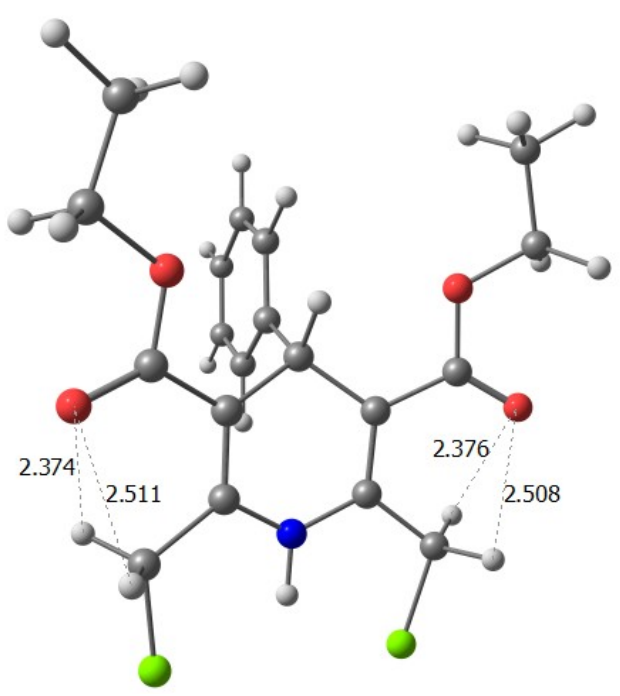

1f

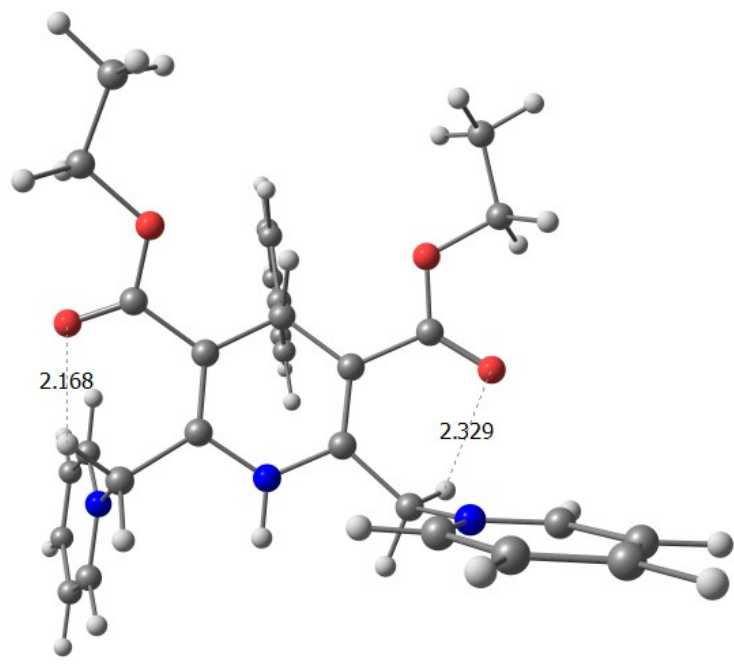

2f

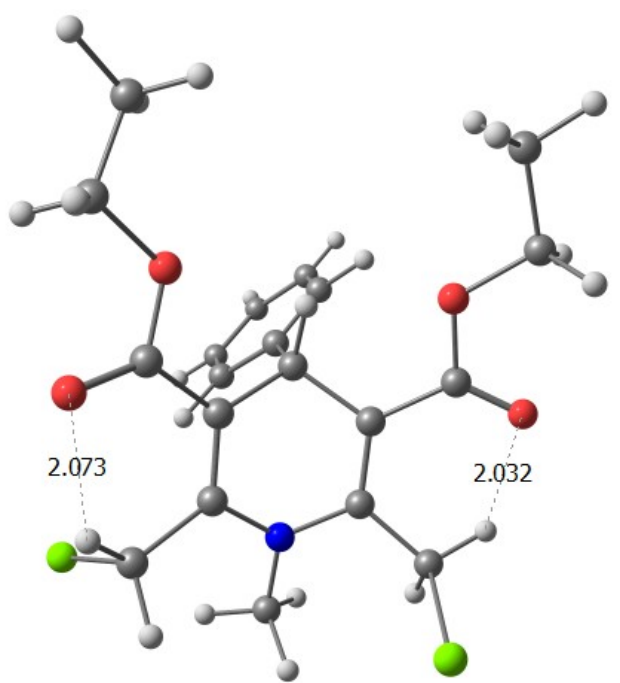

1b

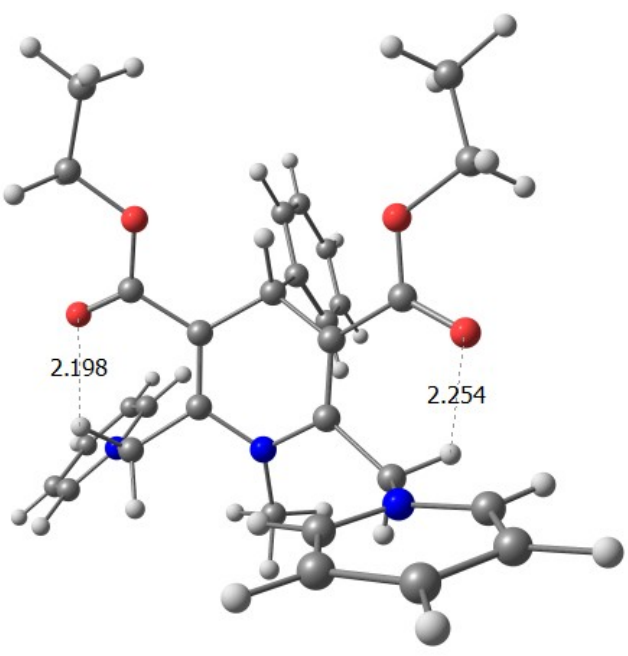

2b 
Analysis of NOEs in the ${ }^{1} \mathrm{H}$ NOESY spectra of compounds 1-3 allows us to determine the relative position of the $\mathrm{AB}$ protons for the methylene group - the NOE from $\mathrm{NH}$ to the more shielded proton $\mathrm{H}_{\mathrm{A}}$ is twice as intense as the $\mathrm{H}_{\mathrm{B}}$ (Figure 2). This means that the $\mathrm{H}_{\mathrm{A}}$ proton resonating in a lower-frequency field is located closer to the $\mathrm{NH}$ proton by about 0.3 angstroms.

Figure 2. Slice of ${ }^{1} \mathrm{H}-\mathrm{NMR}$ NOESY spectrum for compound $\mathbf{3 b}$. More intense NOE is registered between $\mathrm{NH}$ and $\mathrm{H}_{\mathrm{A}}$, showing preferable orientation toward the $\mathrm{NH}$.

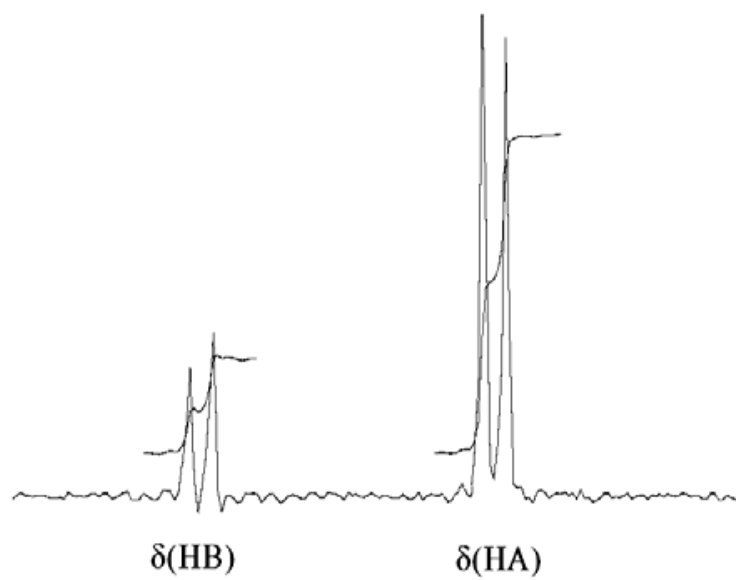

Such an arrangement of $\mathrm{CH}_{2}$ protons leads to an intramolecular contact between the hydrogen atom $\mathrm{H}_{\mathrm{B}}$ and the carboxyl group at the $\mathrm{C} 3$ carbon, leading to the formation of a $\mathrm{CH}_{\mathrm{B}} \cdots \mathrm{O}=\mathrm{C}$ hydrogen bond. It is known that protons involved in hydrogen bonds are less shielded, as compared to free ones [14]. Short interactions of C-H...O play an important role in biology and have been observed in many cases previously [15].

Additional confirmation for the existence of $\mathrm{C}-\mathrm{H} \cdots \mathrm{O}$ hydrogen bonding in compounds $\mathbf{1}-\mathbf{3}$ comes from the different deuteration rates of the 2(6)- $\mathrm{CH}_{2}$ protons (Figure 3). In $\mathrm{D}_{2} \mathrm{O}$ solution the intensity of the resonance signal of the more shielded proton $\mathrm{H}_{\mathrm{A}}$ of compound $\mathbf{3} \mathbf{b}$ decreases faster than for the more deshielded $\mathrm{H}_{\mathrm{B}}$. This is because the hydrogen-bonded protons are usually less influenced by the intermolecular $\mathrm{H}-\mathrm{D}$ exchange. This fact confirms the formation of a hydrogen bond between $\mathrm{H}_{\mathrm{B}}$ methylene proton and the carboxyl group.

Figure 3. ${ }^{1} \mathrm{H}-\mathrm{NMR}$ spectral data of $\mathrm{D}_{2} \mathrm{O}$ solutions of compound $\mathbf{3 b}$ at $25^{\circ} \mathrm{C}$.

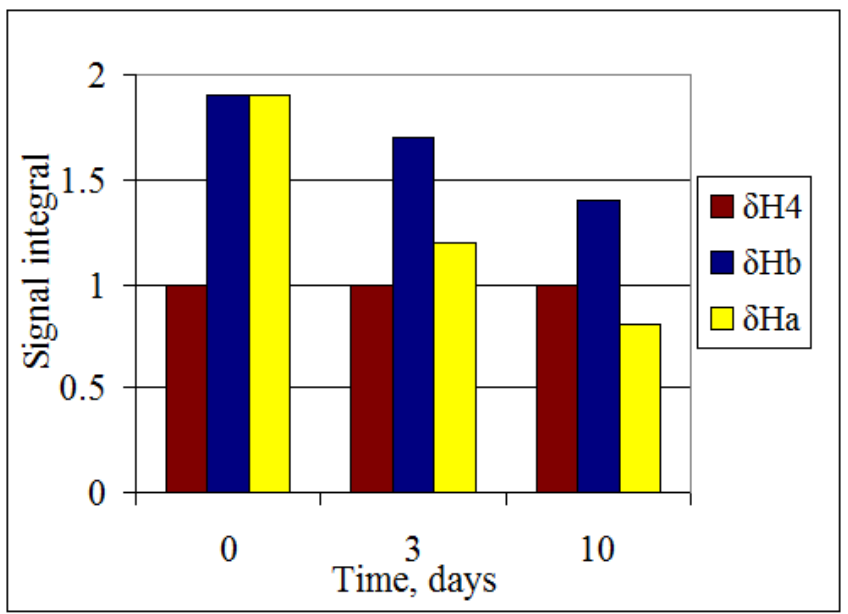


The measured coupling constants ${ }^{1} J\left({ }^{13} \mathrm{C},{ }^{1} \mathrm{H}\right)$ for each of the methylene protons also differ ${ }^{1} J\left({ }^{13} \mathrm{C},{ }^{1} \mathrm{H}_{\mathrm{A}}\right)<{ }^{1} J\left({ }^{13} \mathrm{C},{ }^{1} \mathrm{H}_{\mathrm{B}}\right)$ (see Table 2). The smaller ${ }^{1} J\left({ }^{13} \mathrm{C},{ }^{1} \mathrm{H}\right.$ ) value corresponds to the more shielded proton $\mathrm{H}_{\mathrm{A}}$. This is consistent with the literature data [16], which states that if the $\mathrm{CH}$-proton is involved in a hydrogen bond, the ${ }^{1} J\left({ }^{13} \mathrm{C},{ }^{1} \mathrm{H}\right)$ value increases.

${ }^{1} \mathrm{H}-{ }^{13} \mathrm{C}-\mathrm{HMBC}$ spectra reveal a more intensive magnetization transfer from the low field $\mathrm{H}_{\mathrm{B}}$ proton to ${ }^{13} \mathrm{C}_{3}$ carbon as compared to $\mathrm{H}_{\mathrm{A}}$. It is known that the intensities of cross peaks in the HMBC spectra are proportional to the value of the vicinal coupling constant ${ }^{3} J\left({ }^{13} \mathrm{C},{ }^{1} \mathrm{H}\right)$, normally being ${ }^{3} J(\mathrm{C}, \mathrm{H})_{\text {trans }}>{ }^{3} J(\mathrm{C}, \mathrm{H})_{\text {cis }}[17]$. The delay value used to generate long-range spin-spin interaction between ${ }^{13} \mathrm{C}$ - ${ }^{1} \mathrm{H}$ in $\mathrm{HMBC}$ spectrum was $8 \mathrm{~Hz}$. The higher intensity of $\mathrm{H}_{\mathrm{A}}$ cross peak to the carbon $\mathrm{C}_{3}$ (110.1 ppm) points to its trans-orientation relative to $\mathrm{C}_{3}$. Therefore, the orientation of the less shielded proton $\mathrm{H}_{\mathrm{B}}$ favours its participation in the $\mathrm{CH} \cdots \mathrm{O}$ hydrogen bond.

Thus, on the basis of these data, we can unambiguously claim that the intramolecular $\mathrm{CH} \cdots \mathrm{O}$ hydrogen bond is one of the reasons for the non-equivalence of the methylene protons in these systems. In compounds 1 and 2 the difference in the chemical shifts of the AB methylene protons $\left(\Delta \delta_{\mathrm{AB}}=\delta_{\mathrm{B}}-\delta_{\mathrm{A}}\right)$ vary in the range $0-0.5 \mathrm{ppm}$, rather randomly, depending on the nature of substituents and the solvent used. In compounds 3a-d, with bulk aliphatic substituents at $\mathrm{C}_{3,5}$, the difference is relatively constant and is equal to $\sim 0.5 \mathrm{ppm}$ (Table 2 ). To get more insight for the results obtained by NMR quantum-chemical calculations were carried out.

The results obtained reveal that for compounds $\mathbf{2 b}, \mathbf{2} \mathbf{f}$ the energy minima correspond to the conformations with s-cis-s-cis carboxyl group orientation relative to the double bond in the dihydropyridine cycle, indicating the dominant stabilizing effect of intramolecular hydrogen bond on the conformation of molecules $\mathbf{2 b}, \mathbf{2} \mathbf{f}$ the same as in case of $\mathbf{1 b}, \mathbf{1 f}$. Structures with s-cis-s-trans and s-trans-s-trans carboxyl groups orientation are with higher energy, consequently the stabilizing effect in solutions has to be attributed to the hydrogen bonds $\mathrm{C}-\mathrm{H} \cdots \mathrm{O}$. The calculated equilibrium conformations and the internuclear distances $\mathrm{R}(\mathrm{CH} \cdots \mathrm{O})$ also reveal the formation of a hydrogen bond (Table 3).

In description of hydrogen bonds of the $\mathrm{CH}$.. O type geometric characteristics are often used. In our case, the calculated parameters of intramolecular hydrogen bonds for compounds $\mathbf{1 b}, \mathbf{1 f}, \mathbf{2 b}, \mathbf{2} \mathbf{f}$ and $\mathbf{3 b}$, presented in Table 3, are consistent with the X-ray diffraction and NMR spectral data. According to calculations, the distance $\mathrm{d}(\mathrm{CH} \cdots \mathrm{O})$ decreases, and the angle $(\mathrm{C}-\mathrm{H} \cdots \mathrm{O})$ increases on going from $\mathbf{1 f}, \mathbf{1 b}$ to $\mathbf{3 b}$, indicating weakening of the hydrogen bond between the methylene $\mathrm{H}_{\mathrm{B}}$ proton and oxygen of the carboxyl group. At the same time, in the most energetically favourable conformations of $\mathbf{2} \mathbf{b}, \mathbf{2} \mathbf{f}$ and $\mathbf{3 b}$ there exist additional H-bonds between the pyridine ortho protons and the oxygen atoms of the carboxyl group (see Table 3). These additional H-bonds also stabilize the structure of the molecule. In conformations with s-cis-s-trans and s-trans-s-trans orientation of the carboxyl groups relative to the double bonds of DHP cycle there is a possibility to form H-bonds with a length of about $2.400 \AA$ between protons in position 4 and the ethoxycarbonyl oxygen. The latter contact is much weaker than the ones with protons of the methylene groups and does not contribute significantly to the conformation of the molecule.

In summary, some novel derivatives of 1,4-dihydropyridine bearing substituents at 2,6-methylene groups were synthesized. It was shown that one of the reasons for the diastereotopy of the methylene protons at positions 2 and 6 of symmetrically substituted 1,4-dihydropyridine rings is the formation of 
an intramolecular hydrogen bond of the $\mathrm{CH} \cdots \mathrm{O}$ type, which was confirmed by NMR spectroscopy and quantum-chemistry calculations.

\section{Experimental}

\subsection{Chemicals}

All reagents were purchased from Aldrich, Acros, Fluka or Merck and used without further purification. TLC was performed on $20 \times 20 \mathrm{~cm}$ silica gel TLC-PET F254 foils (Fluka). Melting points were determined on an SRS OptiMelt apparatus (Stanford Research Systems, Sunnyvale, CA, USA). Elemental analyses were performed on an EA 1106 (Carlo Erba Instruments, Milan, Italy). Compounds were recrystallized from methanol, acetone or purified by column chromatography.

\subsection{NMR Experiments (Table 2)}

The one-dimensional ${ }^{1} \mathrm{H}$ - and ${ }^{13} \mathrm{C}$ - and two dimensional ${ }^{1} \mathrm{H}-{ }^{1} \mathrm{H}$ NOESY, ${ }^{13} \mathrm{C}-{ }^{1} \mathrm{H} \mathrm{HMBC},{ }^{13} \mathrm{C}-{ }^{1} \mathrm{H}$ HSQC of compounds 1-5 were recorded on a Varian-Mercury $400 \mathrm{MHz} \mathrm{BB}$ instrument. The mixing time in the 2D-NOESY spectra was $800 \mathrm{~ms}$. The ${ }^{13} \mathrm{C}$-HMBC were recorded with the evolution time of $62.5 \mathrm{~s}$ delay for the generation of long-range correlations. For all two dimensional spectra a $4,096 \times 1,024$ data matrix was used. To improve the signal-noise ratio, the data matrix before Fourier transformation was zero-filled twice and multiplied by a cosine function. The chemical shifts of the hydrogen and carbon atoms are presented in ppm and referred to the residual signals of the solvent a $7.25\left({ }^{1} \mathrm{H}\right)$ and $77.0 \mathrm{ppm}\left({ }^{13} \mathrm{C}\right) \mathrm{ppm}$, respectively. Multiplicities are abbreviated as: s, singlet; d, doublet; t, triplet; q, quartet; m, multiplet; br, broad. The coupling constants are expressed in Hertz.

\subsection{Synthesis}

General method for the synthesis of 2,6-di(bromomethyl)-3,5-bis(alkoxycarbonyl)-4-aryl(4-alkyl)-(or N-methyl)-1,4-dihydropyridines 1a-d,i: To a solution of the appropriate 2,6-dimethyl-3,5bis(alkoxycarbonyl)-4-aryl(4-alkyl)-1,4-dihydro-pyridine $(5 \mathrm{mmol})$ in methanol $(50 \mathrm{~mL})$ NBS (10 mmol) was added portionwise at ambient temperature. The reaction mixture was stirred at $\mathrm{rt}$ for $24 \mathrm{~h}$. The pale yellow precipitate was filtered and washed with water. The precipitate was crystallized from ethanol giving 1a-d,i.

2,6-Di(chloromethyl)-3,5-bis(ethoxycarbonyl)-4-methoxycarbonyl-1,4-dihydropyridine (1e). A mixture of ethyl 4-chloroacetoacetate $(2.72 \mathrm{~mL}, 20 \mathrm{mmol})$ and glyoxylic acid monohydrate $(1.74 \mathrm{~g}, 19 \mathrm{mmol})$ in methanol $(40 \mathrm{~mL})$ was stirred at $\mathrm{rt}$ for $72 \mathrm{~h}$ in the presence of piperidine/acetate as catalyst. Then ethyl (E,Z)-3-amino-4-chlorobut-2-enoate (3.27 g, $20 \mathrm{mmol})$ was added and the combined mixture was stirred at $\mathrm{rt}$ additional $72 \mathrm{~h}$. The solvent was removed under vacuum and the residue was washed with water. The obtained yellow oil was crystallized from methanol yielding 3,5-diethyl 2,6-bis(chloromethyl)-1,4-dihydropyridine-3,4,5-tricarboxylate (4.98 g, 68\%); m.p.164-166 ${ }^{\circ} \mathrm{C}$; elemental analysis calcd (\%) for $\mathrm{C}_{14} \mathrm{H}_{17} \mathrm{Cl}_{2} \mathrm{NO}_{6}$ : $\mathrm{C} 45.92, \mathrm{H} \mathrm{4,68,} \mathrm{N} 3.82$; found: $\mathrm{C} 45.95, \mathrm{H} 4.58, \mathrm{~N} 3.72$. To a solution of 3,5-diethyl 2,6-bis(chloromethyl)-1,4-dihydropyridine-3,4,5-tricarboxylate (1.83 g, $5 \mathrm{mmol})$ in methanol $(30 \mathrm{~mL})$ conc. sulfuric acid $(0.1 \mathrm{~mL})$ was added and the reaction mixture was 
refluxed for $2 \mathrm{~h}$. The solvent was removed under vacuum and the residual crude product was triturated with water. After cooling the precipitate was filtered off and crystallized from methanol giving compound 1e (1.65 g, 87\%); m.p. $99-101{ }^{\circ} \mathrm{C}$; p elemental analysis calcd. (\%) for $\mathrm{C}_{15} \mathrm{H}_{19} \mathrm{Cl}_{2} \mathrm{NO}_{6}$ : $\mathrm{C}$ 47.38, H 5.04, N 3.68; found: C 47.41; H 4.95; N 3.68.

General method for the synthesis of 1,1 '-\{[3,5-bis(alkoxycarbonyl)(3,5-bis(2-propoxyethoxycarbonyl)4-aryl(4-alkyl) (or N-methyl)-1,4-dihydropyridine-2,6-diyl] dimethylene\} bispyridinium dibromides $\mathbf{2 a - d , h : ~ T o ~ a ~ s o l u t i o n ~ o f ~ c o m p o u n d s ~} \mathbf{1 a}-\mathbf{d}, \mathbf{i}(2 \mathrm{mmol})$ in dry acetone $(20 \mathrm{~mL})$ pyridine $(0.20 \mathrm{~mL}, 2.2$ $\mathrm{mmol}$ ) was added and the reaction mixture was stirred at $\mathrm{rt}$ for $24 \mathrm{~h}$. After cooling the precipitate was filtered off, washed with dry acetone and crystallized from ethanol giving compounds $\mathbf{2} \mathbf{a}-\mathbf{d}, \mathbf{h}$ as pale yellow powders.

1,1 '-\{[3,5-Bis(ethoxycarbonyl)-4-methoxycarbonyl-1,4-dihydropyridine-2,6-diyl]dimethylene\} bispyridinium diiodide (2e). To a solution of compound $1 \mathbf{e}(0.38 \mathrm{~g}, 1 \mathrm{mmol})$ in dry acetone $(4 \mathrm{~mL})$ pyridine $(0.18 \mathrm{~mL}, 2 \mathrm{mmol})$ and potassium iodide $(0.33 \mathrm{~g}, 2 \mathrm{mmol})$ were added and the mixture was stirred at $\mathrm{rt}$ for $48 \mathrm{~h}$. The mixture was diluted with acetone $(20 \mathrm{~mL})$, and the potassium chloride formed was filtered off. Acetone was removed under vacuum, and the residue was crystallized from methanol yielding compound $2 \mathrm{e}$ as a pale yellow powder, (0.65 g, 91\%); m.p.137-139 ${ }^{\circ} \mathrm{C}$; elemental analysis calcd (\%) for $\mathrm{C}_{25} \mathrm{H}_{29} \mathrm{I}_{2} \mathrm{~N}_{3} \mathrm{O}_{6}$ : C 41.63; H 4.05; N 5.83; found: $\mathrm{C} 41.49 ; \mathrm{H} 3.98 ; \mathrm{N}$ 5.65.

\subsection{Computional Methods}

The Firefly (7.1.G) software package [18] was used for calculation/optimisation of structures/structures' geometry. The structures of $\mathbf{1 d}, \mathbf{1 e}, \mathbf{1 d}$ and $\mathbf{2 a}$ were optimised using a combined RHF/DFT (b3lyp) method and 6-31g basis set. In the calculation of compounds $\mathbf{1}$ and $\mathbf{2}$ the basis set was supplemented by two polarization functions $(* *)$ and a diffuse $(++)-6-31 \mathrm{~g}++* *$ (hybrid DFT/RHF B3LYP/6-31++G**). For $3 \mathbf{b}$ the same method and theory level was used, only simplified by using one polarization function and one diffuse - (hybrid DFT/RHF B3LYP/6-31+G*).

\section{Conclusions}

Some novel derivatives of 1,4-dihydropyridine were synthesized. Due to the presence of a prochiral centre at $\mathrm{C}-4$ in the heterocyclic ring magnetic non-equivalence of the diastereotopic methylene protons in positions 2 and 6 was observed. NMR spectroscopy and quantum-chemistry calculations confirmed that the formation of a $\mathrm{CH}^{\cdots} \mathrm{O}$ intramolecular hydrogen bond amplifies the extent of the anisochrony of the methylene protons.

\section{Acknowledgments}

This work was supported by the ESF project No.2009/0197/1DP/1.1.1.2.0./09/APIA/VIAA/014 "Design of new pharmacomodulators and studies of their nanoassociates as transport forms", VPP-4-02.2 and VPP-4-07-3. 


\section{References}

1. Triggle, D.J. The chemist as astronaut: Searching for biologically useful space in the chemical universe. Biochem. Pharmacol. 2009, 78, 217-223.

2. Edraki, N.; Mehdipour, A.R.; Khoshneviszadeh, M.; Miri, R. Dihydropyridines: Evaluation of their current and future pharmacological applications. Drug Discov. Today 2009, 14, 1058-1066.

3. Skrastin'sh, I.P.; Kastron, V.V.; Chekavichus, B.S.; Sausin'sh, A.é.; Zolotoyabko, R.M.; Dubur, G.Y. Bromination of 4-aryl-3,5-dialkoxycarbonyl-2,6-dimethyl-1,4-dihydropyridines Chem. Heterocycl. Comp. 1991, 27, 989-994.

4. Urtti, A.; Hyvonen, Z.; Plotniece, A.; Makarova, N.; Reine, I.; Tirzitis, G.; Vigante, B.; Cekavicus, B.; Shmidlers, A.; Krauze, A.; Zhalubovskis, R.; Duburs, G.; Turunen, M.; Yla-Herttuala, S.; Jaaskelainen, I.; Toppinen, M.R. Cationic amphiphilic 1,4-dihydropyridine derivatives useful for delivery of nucleotide containing compounds. WO 01/62946 A1, 70, 8. 2001.

5. Pajuste, K.; Plotniece, A.; Kore, K.; Intenberga, L.; Cekavicus, B.; Kaldre, D.; Duburs, G.; Sobolev, A. Use of pyridinium ionic liquids as catalysts for the synthesis of 3,5-bis(dodecyloxycarbonyl)-1,4-dihydropyridine derivatives. Cent. Eur. J. Chem. 2011, 9, 143-148.

6. Plotniece, A.; Pajuste, K.; Kaldre, D.; Cekavicus, B.; Vigante, B.; Turovska, B.; Belyakov, S.; Sobolev, A.; Duburs, G. Oxidation of cationic 1,4-dihydropyridine derivatives as model compounds for putative gene delivery agents. Tetrahedron 2009, 65, 8344-8349.

7. Hyvönen, Z.; Plotniece, A.; Reine, I.; Chekavichus, B.; Duburs, G.; Urtti, A. Novel cationic amphiphilic 1,4-dihydropyridine derivatives for DNA delivery. Biochim. Biophys. Acta Biomembr. 2000, 1509, 451-466.

8. Görlitzer, K.; Bartke, U.; Schmidt, E. Zur reaktion von nifedipin mit pyridiniumbromidperbromid. Arch. Pharm. 1991, 324, 105-109.

9. Bystrov, V.F. Spin-Spin coupling between geminal and vicinal protons. Russ. Chem. Rev. 1972, 41, 281-304.

10. Pfister, J.R. Rapid, high-yield oxidation of hantzsch-type 1,4-dihydropyridines with ceric ammonium nitrate. Synthesis 1990, 8, 689-690.

11. Skrastin`sh, I.P.; Kastron, V.V.; Vitolin, R.O.; Dubur, G.Ya.; Stivrinya, M.I.; Kaidaka, K.A. Synthesis and pharmacological activity of furo-1,4-dihydropyridines. Pharm. Chem. J. 1989, 23, 893-896.

12. Martin, N.; Segura, J.L.; Seanone, C.; Soto, J.L.; Morales, M.; Suarez, M. A novel one-step synthesis of $4 \mathrm{H}$-furo[3,4-b]pyrans and a transformation into a difuro[3,4-b: 3',4'-e]pyridine. Liebigs Anna. Chem. 1991, 8, 827-830.

13. Skrastin`sh, I.P.; Kastron, V.V.; Dubur, G.Ya.; Mazheika, I.B.; Liepin`sh, E.E. Bromination of 2,6-dimethyl-3,5-dimethoxycarbonyl-4-(2,-difluoromethoxyphenyl)-1,4-dihydropyridine (foridone). Chem. Heterocycl. Compd. 1989, 25, 791-795.

14. Schaefer, T.; Peeling, J.; Sebastian. R. Relation between hydroxyl proton chemical shifts and torsional frequencies in some ortho-substituted phenol derivatives. J. Phys. Chem. 1975, 79, 1888-1890. 
15. Leroy, I.L.; Snoussi, K.; Gueron, M. Investigation of the energetics of $\mathrm{C}-\mathrm{H} \cdots \mathrm{O}$ hydrogen bonds in the DNA i-motif via the equilibrium between alternative intercalation topologies. Magn. Reson. Chem. 2001, 39, 171-176.

16. Afonin, A.V.; Ushakov, I.A.; Simonenko, D.E.; Shmidt, E.Y.; Zorina, N.V.; Mikhaleva, A.I.; Trofimov, B.A. ${ }^{1} \mathrm{H}$ and ${ }^{13} \mathrm{C}$ NMR Study of bifurcated intramolecular hydrogen bonds in 2,6-bis(2pyrrolyl)pyridine and 2,6-bis(1-vinyl-2-pyrrolyl)pyridine. Russ. J. Org. Chem. 2005, 41, 1516-1521.

17. Marshall, J.L. Carbon-Carbon and Carbon-Proton NMR Coupling. Methods in Stereochemical Analysis 2; Verlag Chemie International: Weinheim, Germany, 1983; p. 241.

18. Granovsky, A.A. Firefly version 7.1.G. Available online: www http://classic.chem.msu.su/gran/ firefly/index.html (accessed on 7 September 2011).

(C) 2011 by the authors; licensee MDPI, Basel, Switzerland. This article is an open access article distributed under the terms and conditions of the Creative Commons Attribution license (http://creativecommons.org/licenses/by/3.0/). 